\title{
Bacillus Spores in the Mail: "Ironing" Out the Anthrax Problem
}

\author{
Marc R. Roberge
}

\section{ABSTRACT}

Introduction: Following a terrorist release of Bacillus anthracis spores through the U.S. Postal Service, it was suggested that decontamination of spores in mail envelopes could be accomplished at home by utilizing the steam heat from a household iron. This study investigated the use of a standard household iron, in a dry heat mode, for sterilizing mail envelopes laced with bacterial spores.

Methods: The Bacillus subtilis var. niger spore, a more heat resistant spore, was used as a surrogate for $B$. Anthracis spores. Standard mail envelopes containing $2.1 \times 10^{6}$ spores were sealed and subjected to various levels of dry heat from a standard household iron for periods of 5, 10, and 15 minutes. Envelope contents were then cultured in soy broth for seven days to detect any bacterial growth, and in addition envelopes and contents were visually inspected for evidence of damage and readability of words.

Results: At a temperature range of $160.01^{\circ} \mathrm{C}-204.5^{\circ} \mathrm{C}$ for a period of 5 minutes, $B$. subtilis var. niger spores were effectively sterilized and, at 7 days, no bacterial growth was observed. No gross evidence of envelope damage was observed and the legibility of words was not compromised.

Conclusions: Dry heat from a common household iron is capable of destroying Bacillus spores in mailing envelopes without grossly altering the envelope or affecting the legibility of words.

\section{INTRODUCTION}

In 2001, the U.S. Postal Service became a focal point of bioterrorism activity when Bacillus anthracis spores (Anthrax) were sent to various locales in the U.S. via mail envelopes [1]. Subsequently, 23 individuals (5 of whom died) were reported to be infected with cutaneous and pulmonary Anthrax; however, the contention has been made that (given those individuals who tested positive for anthrax via nasal swabs were subsequently treated) the true number of infected individuals was 68 [2]. On October 12, 2001, Ken Alibek, a former Soviet germ warfare scientist, spoke at a U.S. Congressional briefing on nonproliferation and told members of the briefing that individuals concerned about contaminated mail could use a hot steam iron and moist fabric to kill anthrax spores [3]. This comment has been frequently repeated in the press and has spawned articles, both pro and con, in the press and on the Internet [4-6]. To the best of our knowledge, there are not any studies that have evaluated the spore-killing capability of a conventional household iron set on a dry mode. The current study was undertaken to determine if a common household iron, in dry heat mode, was capable of destroying Bacillus subtilis var niger spores contained in standard mailing envelopes, and to ascertain any deleterious effects upon envelope integrity and the legibility of hand-written and printergenerated words.

Keywords: bacillus subtilis var. niger, anthrax, household iron, mail envelopes

Notes: This data was presented at the Pennsylvania Junior Academy of Sciences State Finals, Pennsylvania State University, May 16, 2005. Marc Roberge is a senior at Central Catholic High School in Pittsburgh. Marc would like to thank his parents (Dr. Raymond and Mary Roberge) and his high school science teacher, Mr. Kortec, for supporting him and mentoring his intellectual curiosity. Marc would also like to thank Professor John Wilson of the University of Pittsburgh for his assistance with the statistical analysis of experimental results. Marc's experiences with his parents, teachers, and members of the scientific community have reinforced his desire to pursue a career in medicine and medical research.

Corresponding author: Marc R. Roberge, 5909 Hampton Street, Pittsburgh, PA 15206. Email: hunter_5988@yahoo.com 


\section{MATERIALS AND METHODS}

Paper strips impregnated with Bacillus subtilis var. niger spores $\left(2.1 \times 10^{6}\right.$ spore populations) contained in individual sterile, sealed, glassine packets were obtained from a biotech firm (SGM Biotech, Inc., Bozeman, MT). A single spore strip (in its glassine envelope) was aseptically placed within a double-folded, single sheet of standard, white writing paper $(20.3 \mathrm{~cm} \times 30.5 \mathrm{~cm}$ width $)$ inscribed with wording from a printer (Model 845c Deskjet ${ }^{\circledR}$, Hewlett-Packard Corporation, Palo Alto, CA). The spore strip/ letter combination was then transferred into a standard white $(10.4 \mathrm{~cm} \times 24.1 \mathrm{~cm})$ mailing envelope (Mead Corporation, Dayton, $\mathrm{OH}$ ) inscribed with wording from a ballpoint pen. The envelope was immediately sealed after moistening the envelope adhesive with sterile water and applying tactile pressure. Individual envelopes were subsequently placed upon a standard metal ironing board that was covered with a $100 \%$ polyester pad and 100\% cotton cover (Bajer Design, Pewaukee, WI). A new, not previously used, Rowenta ${ }^{\circledR}$ Model SM700 (120 volts, 1400 watts Rowenta, Inc., Medford, MA) household iron was utilized for the experiments. As per the manufacturer, the 3 individual settings on the iron offer 3 different types of dry heat (high, medium, and low) that fall within a given range (Table 1). Throughout the experiments, the temperature ranges specified by the manufacturer were verified through use of a digital thermometer (Pyrex ${ }^{\circledR}$ Professional ${ }^{\mathrm{TM}}$, Robinson Knife Company, Buffalo, NY). Continuous to-and-fro ironing movements were carried out over the individual envelopes for periods of 5,10 , or 15 minutes: 10 samples at each of the 3 temperature settings were carried out, resulting in a sample size of 90 envelopes (sample size was randomly determined).

After ironing a mailing envelope for the specified time and temperature, the address on the envelope was visually inspected for readability and the envelope seal was evaluated for any gross adhesive breakdowns. Immediately thereafter, the spore strip was aseptically removed from the envelope and glassine packet and placed in a sterile Releasat ${ }^{\circledR}$ media tube (SGM Biotech, Bozeman, MT) containing modified soybean casein digest broth and a color indicator that would turn from its red baseline color to a yellow color if any bacterial growth occurred. Growth could also be visually determined by the presence of turbidity in the media.

TABLE 1. Heat settings for the Rowenta ${ }^{\circledR}$ Model SM700 iron (120 volts, 1400 watts)*

\begin{tabular}{lcc}
\hline & Temperature & Variance \\
\hline High & $160.01^{\circ} \mathrm{C}-204.5^{\circ} \mathrm{C}$ & $\pm 6.7^{\circ}$ \\
\hline Medium & $121.12^{\circ} \mathrm{C}-148.9^{\circ} \mathrm{C}$ & $\pm 6.7^{\circ}$ \\
\hline Low & $79.5^{\circ} \mathrm{C}-110^{\circ} \mathrm{C}$ & $\pm 6.7^{\circ}$ \\
\hline *Manufacturer's data & & \\
\hline
\end{tabular}

As a control, a spore strip that had not undergone ironing was placed in a Releasat ${ }^{\circledR}$ media tube. All media tubes were then placed in an incubator (Model 10-140, Quincy Labs, Inc., Chicago, IL) at $37^{\circ} \mathrm{C}$ for seven days and observed daily for any growth. To further confirm growth and to test the reliability of the color indicator, 10-microliter samples-obtained from one test tube randomly selected from each of the nine time/temperature groups and from the control tube-were then aseptically plated onto individual LB-agar (Luria-Bertani agar) plates on the seventh day. These plates were then incubated for 24 hours, at which time colony counts were performed. A second sample of identical 10-microliter samples from each of the aforementioned 10 randomly selected test tubes was diluted 100-fold. A subsequent 10-microliter sample was then plated onto two additional LB-agar plates for each sample and incubated for 24 hours with subsequent colony counts. For purposes of statistical analyses, colony counts too numerous to count (TNTC) or those with multiple coalescences difficult to ascertain were arbitrarily given a colony count numerical value of 150 colonies. Statistical analyses of the results were carried out using a two-factor ANOVA for independent samples (VassarStats, Poughkeepsie, NY). A p-value of 0.05 was considered statistically significant for the purposes of this study.

\section{RESULTS}

Bacterial growth-as determined visually by a color change in the media (and frequently, concomitant turbidity)—was observed for all test tubes, at all time intervals, in the low and medium temperature ranges of the iron. Color changes were evident within 24 hours for the tubes from the low heat tests and within 48 hours for the tubes from the medium heat tests. No color changes or turbidity were noted in any of the culture tubes, at any time interval, from the high heat tests. The control strip that had not been subjected to any heat tests turned yellow with an associated significant turbidity within 24 hours, indicating bacterial growth. The LB-agar plates containing the undiluted 10-microliter samples from the randomly selected time/temperature tubes demonstrated growth at all time categories for low and medium temperatures, but no growth was noted for the high temperature setting at any time interval. Identical findings were noted for the 100-fold dilutions carried out on the low and medium temperature samples (Table 2). The effect of heat upon $B$. subtilis var. niger spore survivorship was statistically significant $(p=0.000007)$ as was the effect of time upon spore survivorship $(\mathrm{p}=0.01)$, but the combined effect of time and temperature on each other was not significant $(p=0.76)$. No visible effects upon the words of the pen-written or printer-generated ink were evident. The adhesive seal of the envelopes was never noted to separate grossly. Through the use of a digital thermometer, the variability in temperatures' settings on the iron never exceeded $2 \%$ of the manufacturer's stated parameters. 
TABLE 2. Culture results

Culture Media Color Indicator

\begin{tabular}{lccc}
\hline Ironing Time & High Temperature & Medium Temperature & Low Temperature \\
\hline 5 minutes & Red (No Growth) & Yellow (Growth) & Yellow (Growth) \\
\hline 10 minutes & Red (No Growth) & Yellow (Growth) & Yellow (Growth) \\
\hline 15 minutes & Red (No Growth) & Yellow (Growth) & Yellow (Growth) \\
\hline
\end{tabular}

Culture Colony Counts

\begin{tabular}{|c|c|c|c|c|c|}
\hline Ironing Time & $\begin{array}{c}\text { High Temp. } \\
\text { Undiluted Sample }\end{array}$ & $\begin{array}{l}\text { Medium Temp. } \\
\text { Undiluted Sample* }\end{array}$ & $\begin{array}{l}\text { Medium Temp. } \\
\text { 1:100 Dilution** }\end{array}$ & $\begin{array}{l}\text { Low Temp. } \\
\text { Undiluted Sample* }\end{array}$ & $\begin{array}{l}\text { Low Temp. } \\
\text { 1:100 Dilution** }\end{array}$ \\
\hline 5 minutes & No Growth & 87 & 23.5 & $>150$ & $>150$ \\
\hline 10 minutes & No Growth & 60 & 14.5 & $>150$ & 107.5 \\
\hline 15 minutes & No Growth & 49 & 3.5 & 128 & 71.5 \\
\hline \multicolumn{6}{|c|}{${ }^{*}$ denotes single culture } \\
\hline
\end{tabular}

\section{DISCUSSSION}

The spread of infectious agents through the postal system, either unintentionally or intentionally, has been a public health concern for centuries [7]. The U.S. Postal Service's Anthrax incident of 2001 has spawned much discussion and many suggestions concerning various ways of dealing with Anthrax spores sent through the mail. One bioterrorism expert suggested that steam ironing mail envelopes could destroy Anthrax spores, but the required iron temperature and the time of heat exposure were unknown $[3,8]$. The current investigation demonstrated the ability of a common household iron-adjusted to a dry heat temperature setting of $160.4^{\circ} \mathrm{C}-204.5^{\circ} \mathrm{C}$ for a minimum of 5 minutes-to eradicate $B$. subtilis var. niger spores (spore count of $2.1 \times 10^{6}$ ) housed in standard mail envelopes. Although the use of moist heat has been suggested for optimal eradication of Anthrax spores contained in mail envelopes, this study has demonstrated that dry heat is an effective sporicidal agent [3]. Our findings are congruent with prior research that dry heat ranges of $180^{\circ} \mathrm{C}-200^{\circ} \mathrm{C}$ kill Anthrax spores $\left(6 \times 10^{3}\right.$ to $1.2 \times 10^{4}$ spore counts $)$ within 2 minutes [9]. Additionally, dry heat had no visible effect upon the ink of pen-written or printer-generated words on the envelope or on the enclosed letter, whereas the use of steam heat has been shown to affect the quality of ink characters on mail envelopes [10]. Also, dry heat had no grossly visible effect upon the adhesive bond of the envelope; this may have been related to the desiccating effects of the dry heat in reinforcing the adhesive bond.

Statistical analysis of our data suggests that heat and time had independent effects on spore survivorship, such that the minimal time and minimal temperature required for total eradication of Bacillus subtilis var. niger by a household iron is, as yet, undetermined. But at lesser spore counts (i.e., $6 \times 10^{3}$ to $1.2 \times 10^{4}$ ), Anthrax is destroyed within 2 minutes by temperature ranges used in the current study [9]. Given the fact that $B$. subtilis var. niger is more heat resistant than Anthrax, the results of this study suggest that Anthrax spores in mail envelopes could be destroyed through the use of a common household iron at a dry setting of at least $204.5^{\circ} \mathrm{C}$ for a minimum of 5 minutes [11]. Nonetheless, it is important to emphasize that, when confronted with a suspicious mail envelope, the safest approach is to notify the proper authorities [12].

A limitation of this study is that only one type of common household iron was utilized. It may be that some irons do not reach a temperature that will destroy B. subtilis var. niger spores, or some irons may have temperatures that fluctuate more widely than the iron used in this study. Also, the study spore samples were impregnated onto paper strips; it is unknown if a household iron would be as effective with powdered Bacillus spores or weaponsgrade Bacillus spores contained in an envelope. Although no gross separation of the envelope adhesive was noted, it is possible that minute or microscopic separations occurred that were not visible to the naked eye. Lastly, different ink formulations might be more affected by dry heat than those tested in the current study.

\section{CONCLUSION}

The Anthrax postal terrorism incident has spawned much speculation about the elimination of Anthrax detected in the mail. Suggestions have been made that steam-ironing mail with a common household iron can destroy Anthrax spores, but this has been subjected to limited scientific scrutiny [3]. This study has demonstrated that a common household iron, utilized at a 
dry heat setting of at least $204.5^{\circ} \mathrm{C}$ for a minimum of 5 minutes, can destroy $B$. subtilis var. niger spores placed in standard mailing envelopes without causing grossly-evident envelope adhesive separation or having a deleterious effect upon the legibility of pen-written or printer-generated wording. This suggests that the common household iron is capable of destroying Anthrax spores in mail envelopes. Further investigation will be necessary to determine minimum time/heat parameters necessary to destroy $B$. subtilis var. niger or Anthrax spores in mail envelopes.

The author has no potential financial conflicts of interest to report.

\section{REFERENCES}

1. Dewan PK, Fry AM, Laserson K. Tierney BC, Quinn CP, et al: Inhalational anthrax outbreak among postal workers, Washington, D.C., 2001. Emerg Infect Dis 2002; 8:1066-1072.

2. Cymet TC, Kerkvliet GJ: What is the true number of victims of the postal Anthrax attack of 2001? (Letter) J American Osteopath Assoc 2004; 104:452.

3. Alibek K: Combating Terrorism: Assessing the Threat of a Biological Weapons Attack. House Subcommittee on National Security, Veterans Affairs, and International Relations 12 October 2001. www.NewsMax.com/archives/articles/2002/10/21/ 204923.shtml
4. Emery D: "Should I iron my mail to prevent Anthrax?" 17 October 2001. www.urbanlegends.about.com/library/weekly/ aa101701a.htn

5. Strauss V: Anthrax facts: What it is, what to do. The Washington Post 24 October 2001; A15, The Washington Post Company, Washington, DC

6. Mikkelson B: The Steam Genie. 16 October 2001. www.snopes.com/rumors/iron.htn

7. Ambrose CT: Osler and the infected letter. Emerg Infect Dis 2005; 11:1-9.

8. Anonymous: Civil Defense Perspectives: Anthrax, Oregon Institute of Science and Medicine, www.oism.org/cdp/ nov2001.htnl

9. Whitney EAS, Beatty ME, Taylor Jr TH, Weyant R, Sobel J, Arduino MJ, Ashford DA: Inactivation of Bacillus anthracis spores. Emerg Inf Dis 2003; 9:623-627

10. Whitis M: Mail handling in the age of bioterrorism. Accessed at www.freelabs.com/ whitis/biosafety/mail_handling .html

11. Brusch CW: Some biological and physical factors in dry heat sterilization: a general review. Life Sci Space Res 1964; $2: 357-371$.

12. How to recognize and handle a suspicious package or envelope. Centers for Disease Control and Prevention, Atlanta, GA www.bt.cdc.gov/agent/anthrax/mail/suspiciouspackages.asp 